\title{
Firefly bioluminescence outshines aerial predators
}

Gareth S. Powell ${ }^{*}$, Natalie A. Saxton ${ }^{1}$, Yelena M. Pacheco ${ }^{2}$, Kathrin F. Stanger-Hall ${ }^{2}$, Gavin J. Martin ${ }^{3}$, Dominik Kusy ${ }^{4}$, Ladislav Bocak ${ }^{4}$, Marc A. Branham ${ }^{5}$, Seth M. Bybee ${ }^{1}$

${ }^{1}$ Department of Biology and Monte L. Bean Museum, Brigham Young University, 4102 LSB, Provo, Utah, 84602, USA

${ }^{2}$ Plant Biology Department, University of Georgia, 403 Biosciences Building, Athens, GA, 30602, USA

${ }^{3}$ Department of Math and Sciences, Laramie County Community College, 1400 E. College Dr., Cheyenne, WY, 82007, USA

${ }^{4}$ Laboratory of Biodiversity \& Molecular Evolution, Czech Advanced Technology Research Institute CRH, Slechtitelu 27, Palacky University, 78371 Olomouc, Czech Republic

${ }^{5}$ Department of Entomology \& Nematology, University of Florida, P.O. Box 110620, Gainesville, FL 32611, USA

*corresponding author: garethpowell@byu.edu

\section{Abstract}

Bioluminescence is found across life and has many functions. Yet we understand very little about its timing and origins, particularly as a predator avoidance strategy. Understanding the timing between bioluminescence and predator origins has yet to be examined and can help elucidate the evolution of the ecologically important signal aposematism. Using the most prevalent bioluminescent group, fireflies, where bioluminescence primarily functions as aposematic and sexual signals, the timing for the origins of both potential predators of fireflies and bioluminescence is explored. Divergence time estimations were performed using a genomic-scale phylogenetic reconstruction Lampyridae, and multiple fossil calibration points, allowing for a robust estimate for the origin of beetle bioluminescence as both a terrestrial and aerial signal. Our results recover the origins of terrestrial beetle bioluminescence at 141 mya and aerial bioluminescence at 133 mya. These ages predate the origins of all known extant aerial predators (i.e., bats and birds) and support the much older terrestrial predators (frogs, ground beetles, lizards, snakes, and hunting spiders) as the most likely drivers of bioluminescence in beetles.

\section{Keywords}

Aposematism, predation, divergence time estimation, phylogeny, Lampyridae 


\section{Introduction}

Bioluminescence has evolved independently almost 100 times across both eukaryotes and prokaryotes (e.g., insects, crustaceans, other marine invertebrates, fish, protists, fungi, and bacteria; Hastings and Nealson, 1977; Herring, 1987; Haddock et al., 2010; Wilson and Hastings, 1998; Widder, 2010; Lau and Oakley, 2021). The function of bioluminescence varies across organisms including: prey attraction (Lloyd, 1975; Redford, 1982; Faust et al., 2012; Souto et al., 2019), predator avoidance (Grober, 1988; Marek et al., 2011), counterillumination (Jones and Nishiguchi 2004; Martini and Haddock 2017), sexual communication (Lloyd, 1983; Herring, 2007), and spore dispersal (Desjardin et al., 2008; Oliveira et al., 2015). In the terrestrial environment, bioluminescence is principally used as an aposematic signal (Porter and Porter, 1979; Grober, 1988; De Cock and Matthysen, 2001, 2003; Marek et al., 2011; Stanger-Hall and Oakley, 2019).

While Lampyridae (fireflies) are perhaps the most well-known group of bioluminescent beetles, there are four additional extant families that contain bioluminescent species: Elateridae, Sinopyrophoridae, Phengodidae, and Rhagophthalmidae. All known larvae in the Lampyridae, Phengodidae, and Rhagophthalmidae are bioluminescent (Branham and Wenzel, 2001), suggesting larval bioluminescence is the ancestral state for each group or their common ancestor. These larvae are also largely terrestrial. Oba et al. (2020) timed the origin for luciferase at $102.55 \mathrm{MY}$ using seven taxa and a single gene tree (18S). Larval bioluminescence in fireflies of larvae likely originated as a predator avoidance strategy (Branham and Wenzel, 2003; Martin et al., 2017; Oba et al., 2020; Sivinski, 1981). Bioluminescence allows ground dwelling invertebrates to advertise chemical defenses to potential predators (De Cock and Matthysen, 2001, 2003; Marek et al., 2011). For example, Underwood et al. (1997) found that predators learned to avoid distasteful prey when it was associated with light, ultimately resulting in $100 \%$ predator avoidance. This demonstrates the effectiveness of bioluminescence, when accompanied by chemical defenses, as a strong aposematic signal.

Herein we consider larval and larviform or wingless (apterous or brachypterous) females as terrestrial bioluminescence. Adult bioluminescence in fireflies was co-opted for sexual communication in the form of complex aerial bioluminescent courtship displays (called aerial bioluminescence going forward), usually by male fireflies (Branham and Wenzel, 2003). However, there is evidence that adult bioluminescence also accelerates avoidance learning and functions as an aposematic signal for aerial predators (i.e. bats; Moosman et al., 2009; Leavell et al., 2018). 
Potential predators contributing to the origins of terrestrial and aerial (above-ground) bioluminescent signals in fireflies, would have to predate or coincide with the respective origins of terrestrial or aerial bioluminescence. The origin and evolution of terrestrial bioluminescence as an aposematic signal would have been driven by terrestrial predators (e.g., carabid beetles, spiders, amphibians, reptiles, and rodents; Lloyd, 1973). Similarly, in order for aerial bioluminescence to arise as an aposematic signal, aerial predators (e.g., bats, dusk/night active birds; Dillon, 1967; Lloyd, 1973) would have to predate or coincide with the origin of aerial bioluminescence displays. Despite the modern interactions between fireflies and predator groups, none of these predators can yet be attributed to the origin of bioluminescence, terrestrial or aerial, as an aposematic signal in beetles.

Estimating the origins of bioluminescence in fireflies (and close relatives), in relation to the origins of potential predators, is central to understanding the ecology and evolutionary adaptations of bioluminescence as an aposematic visual signal. Here, we take advantage of four described fossils, including one recent elateroid fossil representing the oldest known bioluminescent beetle fossil (see Fossil selection below). These fossils, combined with a recent phylogenomic-scale phylogeny in Lampyridae (Martin et al., 2019), allow for the most robust estimate of the origin of firefly bioluminescence to date. We report potential terrestrial and aerial predator groups at the origins of both terrestrial bioluminescence and aerial bioluminescence in beetles. The results shed light on potential selective agents for firefly bioluminescence, ultimately giving rise to some of the most captivating displays seen in the terrestrial environment.

\section{Material and methods}

\section{Dataset for divergence time estimation}

Bayesian divergence time estimation combines phylogenetic hypotheses with prior knowledge of molecular clocks and/or the fossil record allowing for investigations into the time of origin for organisms and their ecological innovations (Drummond and Rambaut, 2007; Peters et al., 2017). Fossil calibrations are known to have significant impact on divergence time estimation depending on their placement and the age distribution provided (Saladin et al., 2017; Toussaint et al., 2017). Recently described fossils (e.g., Li et al., 2021) and a phylogenetic reconstruction of bioluminescent beetles (Martin et al., 2020) provides us with the opportunity to explore the time of origin for both terrestrial and aerial beetle bioluminescence with greater confidence than ever before. We used an existing large-scale phylogeny to estimate the age for the origin of bioluminescence. Tree files were obtained from Martin et al. (2019), who focused on sub-familial placement and tribes within Lampyridae. 


\section{Fossil selection}

We placed a total of four fossils across the topology (see Table 2). Other described fossils were not included (e.g., Heer, 1849; Wickham, 1912) when older fossil representatives were used. Fossil calibrations were placed on topologies based on morphological similarities with extant taxa discussed within the literature and their currently proposed placements. We placed one fossil at the base of Luciolinae (Protoluciola albertalleni; Kazantsev, 2015) and one at the node Phengodidae + Rhagophthalmidae (Cretophengodes azari; Li et al., 2021). We also placed a fossil at the base of the subfamily Lamprohizinae (Lamprohiza fossilis; Beier 1952; Fanti, 2017), and a fourth at the base of an extant genus (Photinus), using the fossil Photinus kazantsevi (Alekseev, 2019).

We obtained relative ages for each fossil from the age of each deposit provided by Paleobiology Database (Clapman, 2020). When using fossil specimens as calibration points, the relative ages of those deposits can be used as "hard" minimums as there is no need to sample ages younger than the fossil evidence being used; maximum ages are "soft" allowing the divergence time estimation to sample ages older than that proposed maximum, but do so by decreasing the probability of those ages as they get further from that maximum age (Ho and Phillips, 2009). Exponential fossil priors with hard minimums were placed on the following groups across both topologies; (Lamprohiza + Phausis), Luciolinae, Photinus, and (Rhagophthalmidae + Phengodidae). Soft maximum ages for the subfamily and family level fossils were placed at 223 mya based on the oldest known Polyphagan beetles (Chatzimanolis et al., 2012). We also used a soft maximum for the Photinus calibration, set to the age of the oldest known Lampyridae (99 mya) (Li et al., 2021).

\section{Divergence time estimation}

We used chronoPL implemented in the R package APE (Paradis and Schliep, 2019) to give relative node ages to the Martin et al. (2019) topology to ensure our starting node ages were within the bounds of the fossil prior distributions for subsequent analyses (Brewer et al., 2012; Huie et al., 2020). The resulting ultrametric trees from chronoPL were used as fixed topologies in subsequent Baysian analysis to estimate divergence times (Bouchaert et al., 2019). BEAUTi (Bouchaert et al., 2019) was employed to set analysis parameters such as fossil placement and tree models. Multiple combinations of tree and clock models were used to check the sensitivity to model choice. To estimate a rooted time-calibrated phylogeny we used BEAST v.2.6.0 (Bouckaert et al. 2019) via the CIPRES Science Gateway v.3.3 (www.phylo.org). Analyses were run with a chain length of 200,000,000, and to ensure convergence of our analyses the log file for each analysis was viewed in Tracer v.1.7.1 (Rambaut et al., 2018). ESS values $>200$ were 
considered sufficiently converged. Lastly, TreeAnnotator v.1.10.4 (Bouckaert et al., 2014) was used to generate consensus trees after a burn-in of $10 \%(20,000,000)$ was discarded.

\section{Ancestral state reconstruction}

Terrestrial and aerial bioluminescence was coded for the extant taxa in our phylogeny based on whether a light organ was present/absent in the terrestrial larvae (or larviform females) and/or the aerial adults respectively. The resulting matrix was analyzed in Mesquite v.3.6 using both parsimony and maximum likelihood ancestral state reconstructions (Maddison and Maddison, 2019).

\section{Potential predators}

If beetle bioluminescence arose to advertise a chemical defense in terrestrial, firefly larvae then there must have been predation pressure by terrestrial predators selecting for this trait. Adult bioluminescence is used during aerial displays (often by males), and these aerial bioluminescent individuals are preyed upon by aerial predators. Terrestrial and aerial animal groups (e.g., insectivores) known to prey on fireflies were compiled from Day (2011), Lloyd (1973) and authors' observations (see results). Extinct insectivorous groups (e.g., Pterosauria) were also considered. To assess the potential role of each predatory group in the origin of beetle bioluminescent displays, predator group ages were compared with our estimates for the origin of terrestrial and aerial bioluminescence. The ages of each firefly predator group were gathered from the literature (Coddington and Levi, 1991; Evans, 2003; Teeling et al., 2005; Pyron, 2011; dos Reis et al., 2012; Prum et al., 2015; Toussaint et al., 2017)

\section{Results and Discussion}

Terrestrial bioluminescence is an ancestral trait in Lampyridae (and their relatives: Phengodidae, and Rhagophthalmidae) preceding the origin of adult aerial bioluminescence (Figure $1 \&$ Supp Figure 1) that is used widely as a sexual signal in modern fireflies (Branham et al., 2001; 2003; Stanger-Hall and Lloyd 2015). Our results recover the terrestrial bioluminescence at $\sim 141.17$ (122.63-161.17) mya. This was followed by the origin of aerial bioluminescence at $\sim 133.18$ (117.86-152.47) mya (Figure 1).

\section{Divergence time estimation}

Accurate divergence time estimation relies on a combination of broad taxon sampling, an accurate phylogenetic reconstruction, and sufficient breadth and depth of fossil sampling (Lemmon et al., 2009; Heath et al., 2008; Saladin et al., 2017; Toussaint et al., 2017). The limitations of the fossil record, reliable placement of extinct taxa, and immense extant diversity for a group like Elateroidea $(21,000$ described species), have led to continued confusion and disagreement for the ages of these groups. 
Previous estimates for the origin of Elateroidea ranged from 220-130 mya, and estimates for the origin of Lampyridae ranged from 130 -75 mya (Bocak et al., 2016, McKenna et al., 2015). These large ranges were likely due to limited taxon sampling, for both ingroup lampyrids and fossil calibration points used. For example, Bocak et al. (2016), hypothesized the age of Elateroidea to be $\sim 220$ mya and Lampyridae as $\sim 130$ mya based on two extant firefly taxa and a single fossil calibration point (15 gene dataset). Similarly, McKenna et al. (2015) estimated the age of Elateroidea to be $\sim 130$ mya and Lampyridae to be $\sim 78$ mya, with a dataset of four firefly taxa (eight gene dataset). In a subsequent analysis McKenna et al. (2019) reconstructed a phylogeny of Coleoptera and estimated the of Elateroidea to be $\sim 187$ mya and 120 mya for the branch leading to Lampyridae, however, this study included only a single lampyrid species and no internal elateroid fossil calibration, instead utilizing an ancestral click beetle at the base of Elateroidea+Byrroidea (4800 gene dataset).

Our analyses based on Martin et al. (2019) with 436 loci, 88 firefly species (98 taxa total), and four fossil calibrations across the topology recovered a root age for Lampyridae of 133 mya. The divergence time estimates for Lampyridae are older than previously published estimates. McKenna et al. $(2015,2019)$ had limited lampyrid and broader elateroid taxon sampling with limited fossil calibrations that resulted in much younger ages for Lampyridae, and Coleoptera overall, which was already noted by others (Gunter et al., 2016; Toussaint et al., 2017; Che et al., 2021). Our age estimates are closely aligned to the estimates of Bocak et al. (2016), which is likely due to their larger elateroid sampling and ingroup fossil calibration (e.g., Elaterophanes). With updated clade ages, and the species-level biological information gathered for bioluminescence across our phylogeny, we can now examine the validity of previous hypotheses relating to predation and firefly bioluminescence.

\section{Age of bioluminescence in beetles}

Clade ages for bioluminescence were largely congruent between all parameter combinations implemented with minor variations in estimated ages reported between the different clock and tree models (Supp. Table 2). The Yule model does not account for any extinction and elateroid beetles have experienced at least two global extinction events, thus we have focused our discussion going forward on the ages resulting from Birth-Death tree models. The age estimates for each clock model combination largely overlapped for the Birth-Death models, here we discuss the relaxed lognormal clock model here, which has been shown to more precisely estimate ages and is widely used across the discipline (Drummond et al., 2006; Lepage et al., 2007). Our ancestral state reconstruction placed the origin of terrestrial bioluminescence (aposematism) 141.17 mya, during the early Cretaceous period, followed by the origin of aerial bioluminescence (sexual communication in extant fireflies), estimated to be $\sim 133.18$ mya in the common 
ancestor of fireflies. Terrestrial bioluminescence is an ancestral trait in Lampyridae and relatives (Phengodidae, and Rhagophthalmidae) preceding the origin of adult aerial bioluminescence that is used widely as a sexual signal in modern fireflies (Branham et al., 2001, 2003; Stanger-Hall and Lloyd, 2015). Assuming that the original function of bioluminescence was predator deterrence, it begs the question as to what predator, or predators, could have driven the evolution of firefly bioluminescence.

\section{Predators}

Clade ages for potential predators that fireflies likely encountered during their early history, that would have contributed to the origin of bioluminescence as an aposematic signal, were compiled. We identified potential groups of firefly predators that were hypothesized to feed on these groups and prevalent and broad enough in distribution to potentially function as significant firefly predators. Terrestrial predators included: Araneae (spiders) (Coddington and Levi, 1991), Carabidae (carabid beetles) (Toussaint et al., 2017), Anura (frog and toads) (Pyron, 2011), Squamata (lizards and snakes) (Evans, 2003), and Rodentia (dos Reis et al., 2012). Aerial predators included: Aves (birds) (Prum et al., 2015) and Chiroptera (bats) (Teeling et al., 2005). An estimation for the origins of terrestrial bioluminescence allows us to discuss the likeliness of these predator groups as drivers of aposematism. Several diverse terrestrial predator groups, including Anura, Araneae, Carabidae, and Squamata emerged prior to the Jurassic ( $>200$ mya), and therefore could have contributed to the origin of aposematic bioluminescence that arose 141 mya.

In contrast, several other insectivore clades (Aves, Chiroptera, Rodentia) originated much later (<70 mya) than beetle bioluminescence and thus could not have been selective agents in either terrestrial or aerial bioluminescence. It has been suggested that modern aerial predators, specifically bats, could have driven the origin of aerial bioluminescence as a predator avoidance strategy (Leavell et al., 2018). This is contradicted by our data, with bats originating at $\sim 65$ mya (Teeling et al., 2005), considerable after (52-87 million years) the origin of aerial bioluminescence. However, it is possible that once bioluminescence is used by adult fireflies in aerial displays, potential aerial predators like bats and birds can utilize adult firefly bioluminescence as an additional cue to avoid distasteful prey (Leavell et al., 2018). The sensory systems of insectivorous bats can detect both the wavelength of firefly light emissions and the ultrasonic wingbeat clicks emitted by flying fireflies (Hope and Bhatnagar, 1979; Krivoruchko et al., 2021), and they also learn to discriminate flying insects based on their different echo signatures in their echolocation calls (von der Emde and Menne, 1989). Bats have indeed been shown to reject flying fireflies based on their chemical defenses, reinforced by their sonar profile and/or bioluminescent signal that speed up avoidance learning (Leavell et al., 2018). Whether predators like bats impose selection on the aerial bioluminescence of fireflies and possibly contribute to the maintenance of aerial light signals in beetles 
remains to be tested. Other predators such as nocturnal birds and rodents (Lloyd, 1973) that could have preyed on bioluminescent beetles also originated significantly after the origin of both terrestrial and aerial bioluminescence (Fig. 2). For example, modern birds originated $\sim 75$ mya (Prum et al., 2015), and rodents at $\sim 61$ mya (dos Reis et al., 2012), placing them $\sim 65-79$ million years after the estimated origin of terrestrial bioluminescence and $\sim 58-72$ million years after aerial bioluminescence (Fig. 2). Our age estimates for bats, birds, and rodents are almost certainly older than the actual insectivorous lineages within each. Given that larval bioluminescence evolved first and operated in a terrestrial environment, aerial predators, such as bats, could not have been the original receivers or drivers of these aposematic signals. The signal would have been directed toward contemporary predators of elateroids in the early Cretaceous.

There are several extinct vertebrate insectivore groups that could have also preyed on elateroid beetles prior to or during the early Cretaceous (>100 mya) (Brusatte et al., 2015; Xing et al., 2018; Grossnickle et al., 2019). Most of these are limited in both known diversity and distribution in the fossil record and would have only added to the already existing predation pressures in the terrestrial environment. One potential exception could have been the aerial predatory group, Pterosauria. Pterosaurs were the first vertebrate group to develop true flight in the late Triassic ( 227 mya), with the common ancestor of the group hypothesized to be insectivorous (Organ and Shedlock, 2009; Zou et al., 2017). Furthermore, Pterosauria had a broad enough distribution to have encountered bioluminescent beetles (Witton, 2013), and some species are assumed to have been crepuscular or even night (Schmitz and Mortani, 2011), and thus could have been early receivers of the aposematic signals. Although tantalizing, there is no current evidence to support that pterosaurs fed on elateroid beetles.

Our more extensive taxon sampling and well-placed fossils across our topology, recovered more reliable ages for bioluminescent beetles. These ages are older than previous estimations and preclude modern aerial predators as selective agents for the origin of beetle bioluminescence. However, several groups of modern terrestrial predators predate the origin of beetle bioluminescence and thus could have functioned as selective agents for the origin of terrestrial bioluminescence. Based on the present-day use/abundance of terrestrial bioluminescence as aposematic signals and the presence of terrestrial insectivores at the origin of beetle bioluminescence strongly suggests that terrestrial beetle bioluminescence arose as an aposematic signal. In contrast, aerial beetle bioluminescence, which is widely used as a sexual signal during mate search in extant beetles, likely originated as such. We do not rule out that extant insectivores such as bats, birds, and rodents that came after the origin of bioluminescence may operate as contributing factors in conjunction with older predatory groups (e.g., anurans, araneae) that predate beetle 
bioluminescence. What is clear is that the origin of aerial bioluminescence predates any extant aerial predator. Thus, we find that beetle bioluminescence outshines, or predates, the origins of extant aerial predators by roughly 60 million years.

\section{Acknowledgments}

We dedicate this work to the late Dr. Jim Lloyd, the giant of firefly research who mentored us all in significant ways, oftentimes with humor and colorful language. We thank all those that provided specimens or identifications for the original phylogenetic efforts. L.B. and D.K. were partly funded by GACR 18-14942S. This research was in part funded by the National Science Foundation (DEB-1655981 S.M.B; DEB-1655908 K.S.H; and DEB-1655936 M.A.B).

\section{References}

Alekseev, V. I. (2019). New extinct Eocene Coleoptera in Baltic amber of Friedhelm Eichmann's collection (Germany). Baltic Journal of Coleopterology 19(1), 11-22.

Beier, M. (1952). Miozäne und oligozäne Insekten aus Österreich und den unmittelbar angrenzenden Gebieten. Sitzungsberichte, Österreichische Akademie der Wissenschaften, Mathematischnaturwissenschaftiche Klasse, Abteilung I: Biologie, Mineralogie, Erdkunde und verwandte Wissenschaften 161, 129-134.

Bocak, L., Kundrata R., Andújar Fernández C., \& Vogler A. P. (2016). The discovery of Iberobaeniidae (Coleoptera: Elateroidea): a new family of beetles from Spain, with immatures detected by environmental DNA sequencing. Proceedings of the Royal Society of London B-Biological Sciences 283(1830), 20152350.

Branham, M. A., \& Wenzel, J. W. (2001). The evolution of bioluminescence in cantharoids (Coleoptera: Elateroidea). Florida Entomologist, 84(4), 565-586.

Branham, M. A., \& Wenzel, J. W. (2003). The origin of photic behavior and the evolution of sexual communication in fireflies (Coleoptera: Lampyridae). Cladistics, 19(1), 1-22. 
Brewer, M. S., Spruill, C. L., Rao, N. S., \& Bond, J. E. (2012). Phylogenetics of the millipede genus Brachycybe Wood, 1864 (Diplopoda: Platydesmida: Andrognathidae): Patterns of deep evolutionary history and recent speciation. Molecular Phylogenetics and Evolution, 64(1), 232-242.

Brusatte, S. L., O'Connor, J. K. \& Jarvis E. D. (2015). The Origin and Diversification of Birds. Current Biology, 25(19), R888-R898.

Coddington, J. A., \& Levi, H. W. (1991). Systematics and evolution of spiders (Araneae). Annual review of ecology and systematics, 22(1), 565-592.

Chatzimanolis, S., Grimaldi, D. A., Engel, M. S., \& Fraser, N. C. (2012). Leehermania prorova, the earliest staphyliniform beetle, from the Late Triassic of Virginia (Coleoptera: Staphylinidae). American Museum Novitates, 3761(3761), 1-28.

Che, L., Zhang, P., Deng, S., Escalona, H. E., Wang, X., Li, Y., Hong P., Vandenberge, N., Ślipiński, A., Tomaszewska, W., \& Liang, D. (2021). New insights into the phylogeny and evolution of lady beetles (Coleoptera: Coccinellidae) by extensive sampling of genes and species. Molecular Phylogenetics and Evolution, 156, 107045.

Claessens, L. P., O'Connor, P. M., \& Unwin, D. M. (2009). Respiratory evolution facilitated the origin of pterosaur flight and aerial gigantism. PloS one, 4(2), e4497.

De Cock, R., \& Matthysen, E. (2001). Do glow-worm larvae (Coleoptera: Lampyridae) use warning coloration?. Ethology, 107(11), 1019-1033.

De Cock, R., \& Matthysen, E. (2003). Glow-worm larvae bioluminescence (Coleoptera: Lampyridae) operates as an aposematic signal upon toads (Bufo bufo). Behavioral Ecology, 14(1), 103-108.

dos Reis, M., Inoue, J., Hasegawa, M., Asher, R. J., Donoghue, P. C., \& Yang, Z. (2012). Phylogenomic datasets provide both precision and accuracy in estimating the timescale of placental mammal phylogeny. Proceedings of the Royal Society B: Biological Sciences, 279(1742), 3491-3500.

Day, J. C. (2011). Parasites, predators and defence of fireflies and glow-worms (Lampyrid Review Series). Lampyrid, 1, 70-102. 
Desjardin, D. E., Oliveira, A. G., \& Stevani, C. V. (2008). Fungi bioluminescence revisited.

Photochemical \& Photobiological Sciences, 7(2), 170-182.

Drummond, A. J., Ho, S. Y., Phillips, M. J., \& Rambaut, A. (2006). Relaxed phylogenetics and dating with confidence. PLoS Biol, 4(5), e88.

Drummond, A. J., \& Rambaut, A. (2007). BEAST: Bayesian evolutionary analysis by sampling trees. BMC evolutionary biology, 7(1), 1-8.

Evans, S. E. (2003). At the feet of the dinosaurs: the early history and radiation of lizards. Biological Reviews, 78(4), 513-551.

Fanti, F. (2017). World catalog of fossil Cantharidae. Fossils \& Minerals Review, 2(Special Issue), 1-52.

Faust, L., De Cock, R., \& Lewis, S. (2012). Thieves in the night: Kleptoparasitism by fireflies in the genus Photuris Dejean (Coleoptera: Lampyridae). The Coleopterists Bulletin, 66(1), 1-6.

Gunter, N. L., Weir, T. A., Slipinksi, A., Bocak, L., \& Cameron, S. L. (2016). If dung beetles (Scarabaeidae: Scarabaeinae) arose in association with dinosaurs, did they also suffer a mass coextinction at the K-Pg boundary?. PLoS One, 11(5), e 0153570.

Grober, M. S. (1988). Brittle-star bioluminescence functions as an aposematic signal to deter crustacean predators. Animal behaviour, 36(2), 493-501.

Ghiradella, H., \& Schmidt, J. T. (2004). Fireflies at one hundred plus: a new look at flash control. Integrative and Comparative Biology, 44(3), 203-212.

Grossnickle, D. M., Smith, S. M. \& Wilson, G. P. (2019). Untangling the Multiple Ecological Radiations of Early Mammals. Trends in Ecology \& Evolution, 34(10), 936-949.

Haddock, S. H., Moline, M. A., \& Case, J. F. (2010). Bioluminescence in the sea. Annual review of marine science, 2(2010), 443-493. 
Hastings, J. W., \& Nealson, K. H. (1977). Bacterial bioluminescence. Annual review of microbiology, 31(1), 549-595.

Heath, T. A., Hedtke, S. M., \& Hillis, D. M. (2008). Taxon sampling and the accuracy of phylogenetic analyses. Journal of Systematics and Evolution, 46(3), 239-257.

Heer, O. (1849). Die Insektenfauna der Tertiärgebilde von Oeningen und von Radoboj in Croatien: Heuschrecken, Florfliegen, Adlerflügler, Schmetterlinge und Fliegen. W. Engelmann.

Herring, P. J. (1987). Systematic distribution of bioluminescence in living organisms. Journal of bioluminescence and chemiluminescence, 1(3), 147-163.

Herring, P. J. (2007). Sex with the lights on? A review of bioluminescent sexual dimorphism in the sea. Marine Biological Association of the United Kingdom. Journal of the Marine Biological Association of the United Kingdom, 87(4), 829.

Ho, S. Y., \& Phillips, M. J. (2009). Accounting for calibration uncertainty in phylogenetic estimation of evolutionary divergence times. Systematic biology, 58(3), 367-380.

Hope, G. M., \& Bhatnagar, K. P. (1979). Electrical response of bat retina to spectral stimulation: comparison of four microchiropteran species. Experientia, 35(9), 1189-1191.

Huie, J. M., Thacker, C. E., \& Tornabene, L. (2020). Co-evolution of cleaning and feeding morphology in western Atlantic and eastern Pacific gobies. Evolution, 74(2), 419-433.

Jones, B. W., \& Nishiguchi, M. K. (2004). Counterillumination in the hawaiian bobtail squid, Euprymna scolopes Berry (Mollusca: Cephalopoda). Marine Biology, 144(6), 1151-1155.

Kazantsev, S.V. 2015. Protoluciola albertalleni gen.n., sp.n., a new Luciolinae firefly (Insecta: Coleoptera: Lampyridae) from Burmite amber. Russian Entomological Journal, 24(4), 281-283.

Lau, E. S., \& Oakley, T. H. (2021). Multi-level convergence of complex traits and the evolution of bioluminescence. Biological Reviews, 96(2), 673-691. 
Leavell, B. C., Rubin, J. J., McClure, C. J., Miner, K. A., Branham, M. A., \& Barber, J. R. (2018).

Fireflies thwart bat attack with multisensory warnings. Science advances, 5(9), eaat6601.

Lemmon, A. R., Brown, J. M., Stanger-Hall, K., \& Lemmon, E. M. (2009). The effect of ambiguous data on phylogenetic estimates obtained by maximum likelihood and Bayesian inference. Systematic biology, $58(1), 130-145$

Lepage, T., Bryant, D., Philippe, H., \& Lartillot, N. (2007). A general comparison of relaxed molecular clock models. Molecular biology and evolution, 24(12), 2669-2680.

Li, Y. D., Kundrata, R., Tihelka, E., Liu, Z., Huang, D., \& Cai, C. (2021). Cretophengodidae, a new Cretaceous beetle family, sheds light on the evolution of bioluminescence. Proceedings of the Royal Society B, 288(1943), 20202730.

Lloyd, J. E. (1965). Aggressive mimicry in Photuris: firefly femmes fatales. Science, 149(3684), 653654.

Lloyd, J. E. (1966a). Two cryptic new firefly species in the genus Photinus (Coleoptera: Lampyridae). The Coleopterists' Bulletin, 43-46.

Lloyd, J. E. (1966b). Studies on the flash communication system in Photinus fireflies. Miscellaneous Publications Museum of Zoology, University of Michigan, 100 pp.

Lloyd, J. E. (1969). Flashes of Photuris fireflies: their value and use in recognizing species. Florida Entomologist, 52(1), 29-35.

Lloyd, J. E. (1973) Firefly parasites and predators. The Coleopterists' Bulletin, 27(2), 91-106.

Lloyd, J. E. (1975). Aggressive mimicry in Photuris fireflies: signal repertoires by femmes fatales. Science, 187(4175), 452-453.

Lloyd, J. E. (1983). Bioluminescence and communication in insects. Annual review of entomology, 28(1), $131-160$. 
Lloyd, J. E. (1997). 10. Firefly mating ecology, selection and evolution. In J. C. Choe, B. J. Crespi (Eds.) The evolution of mating systems in insects and arachnids. Cambridge University Press, 184-192 pp.

Maddison, W. P. and D.R. Maddison. 2019. Mesquite: a modular system for evolutionary analysis. Version 3.61 http://www.mesquiteproject.org

Marek, P., Papaj, D., Yeager, J., Molina, S., \& Moore, W. (2011). Bioluminescent aposematism in millipedes. Current Biology, 21(18), R680-R681.

Martin, G. J., Branham, M. A., Whiting, M. F., \& Bybee, S. M. (2017). Total evidence phylogeny and the evolution of adult bioluminescence in fireflies (Coleoptera: Lampyridae). Molecular phylogenetics and evolution, 107, 564-575.

Martin, G. J., Stanger-Hall, K. F., Branham, M. A., Da Silveira, L. F., Lower, S. E., Hall, D. W., Li, X., Lemmon, A. R, Lemmon, E. M. \& Bybee, S. M. (2019). Higher-level phylogeny and reclassification of Lampyridae (Coleoptera: Elateroidea). Insect Systematics and Diversity, 3(6), 11.

Martini, S., \& Haddock, S. H. (2017). Quantification of bioluminescence from the surface to the deep sea demonstrates its predominance as an ecological trait. Scientific reports, 7(1), 1-11.

Moosman Jr, P. R., Cratsley, C. K., Lehto, S. D., \& Thomas, H. H. (2009). Do courtship flashes of fireflies (Coleoptera: Lampyridae) serve as aposematic signals to insectivorous bats?. Animal Behaviour, 78(4), 1019-1025.

Oliveira, A. G., Stevani, C. V., Waldenmaier, H. E., Viviani, V., Emerson, J. M., Loros, J. J., \& Dunlap, J. C. (2015). Circadian control sheds light on fungal bioluminescence. Current Biology, 25(7), 964-968.

Organ, C. L., \& Shedlock, A. M. (2009). Palaeogenomics of pterosaurs and the evolution of small genome size in flying vertebrates. Biology letters, 5(1), 47-50.

Paradis E, Schliep K (2019). ape 5.0: an environment for modern phylogenetics and evolutionary analyses in R. Bioinformatics, 35(3), 526-528. 
Peters, R.S., Krogmann, L., Mayer, C., Donath, A., Gunkel, S., Meusemann, K., Kozlov, A., Podsiadlowski, L., Petersen, M., Lanfear, R. and Diez, P.A., (2017). Evolutionary history of the Hymenoptera. Current Biology, 27(7), 1013-1018.

Porter, K. G., \& Porter, J. W. (1979). Bioluminescence in marine plankton: a coevolved antipredation system. The American Naturalist, 114(3), 458-461.

Prum, R. O., Berv, J. S., Dornburg, A., Field, D. J., Townsend, J. P., Lemmon, E. M., \& Lemmon, A. R. (2015). A comprehensive phylogeny of birds (Aves) using targeted next-generation DNA sequencing. Nature, 526(7574), 569-573.

Pyron, R. A. (2011). Divergence time estimation using fossils as terminal taxa and the origins of Lissamphibia. Systematic biology, 60(4), 466-481.

Rambaut, A., Drummond, A. J., Xie, D., Baele, G., \& Suchard, M. A. (2018). Posterior summarization in Bayesian phylogenetics using Tracer 1.7. Systematic biology, 67(5), 901.

Redford, K. H. (1982). Prey attraction as a possible function of bioluminescence in the larvae of Pyrearinus termitilluminans (Coleoptera: Elateridae). Revista Brasileira de Zoologia, 1(1), 31-34.

RStudio Team (2020). RStudio: Integrated Development for R. RStudio, PBC, Boston, MA URL http://www.rstudio.com/

Saladin, B., Leslie, A. B., Wüest, R. O., Litsios, G., Conti, E., Salamin, N., \& Zimmermann, N. E. (2017). Fossils matter: improved estimates of divergence times in Pinus reveal older diversification. BMC evolutionary biology, 17(1), 1-15.

Sivinski, J. (1981). The nature and possible functions of luminescence in Coleoptera larvae. The Coleopterists' Bulletin, 35(2), 167-179.

Stanger-Hall, K. F., Lloyd, J. E., \& Hillis, D. M. (2007). Phylogeny of North American fireflies (Coleoptera: Lampyridae): implications for the evolution of light signals. Molecular phylogenetics and evolution, 45(1), 33-49. 
Souto, P. M., Campello, L., Khattar, G., Mermudes, J. R. M., Monteiro, R. F., \& da Silveira, L. F. L. (2019). How to design a predatory firefly? Lessons from the Photurinae (Coleoptera: Lampyridae). Zoologischer Anzeiger, 278(1), 1-13.

Teeling, E. C., Springer, M. S., Madsen, O., Bates, P., O'brien, S. J., \& Murphy, W. J. (2005). A molecular phylogeny for bats illuminates biogeography and the fossil record. Science, 307(5709), 580584.

Toussaint, E. F., Seidel, M., Arriaga-Varela, E., Hájek, J., Kral, D., Sekerka, L., Short, A.E., Fikáček, M. (2017). The peril of dating beetles. Systematic Entomology, 42(1), 1-10.

Underwood, T. J., Tallamy, D. W., \& Pesek, J. D. (1997). Bioluminescence in firefly larvae: a test of the aposematic display hypothesis (Coleoptera: Lampyridae). Journal of Insect Behavior, 10(3), 365-370.

von der Emde, G., \& Menne, D. (1989). Discrimination of insect wingbeat-frequencies by the bat Rhinolophus ferrumequinum. Journal of Comparative Physiology A, 164(5), 663-671.

Wickham, H. F. (1912). A report on some recent collections of fossil Coleoptera from the Miocene shales of Florissant. Bulletin from the Laboratories of Natural History of the State University of Iowa, 6(3), 338.

Widder, E. A. (2010). Bioluminescence in the ocean: origins of biological, chemical, and ecological diversity. Science, 328(5979), 704-708.

Wilson, T., \& Hastings, J. W. (1998). Bioluminescence. Annual review of cell and developmental biology, 14(1), 197-230.

Witton, M. P. (2013). Pterosaurs: Natural History, Evolution, Anatomy, Princeton University Press, 304 pp.

Xing, L., Stanley, E. L., Bai, M. \& Blackburn, D. C. (2018). The earliest direct evidence of frogs in wet tropical forests from Cretaceous Burmese amber. Sci Rep, 8(8770), 1-8. 


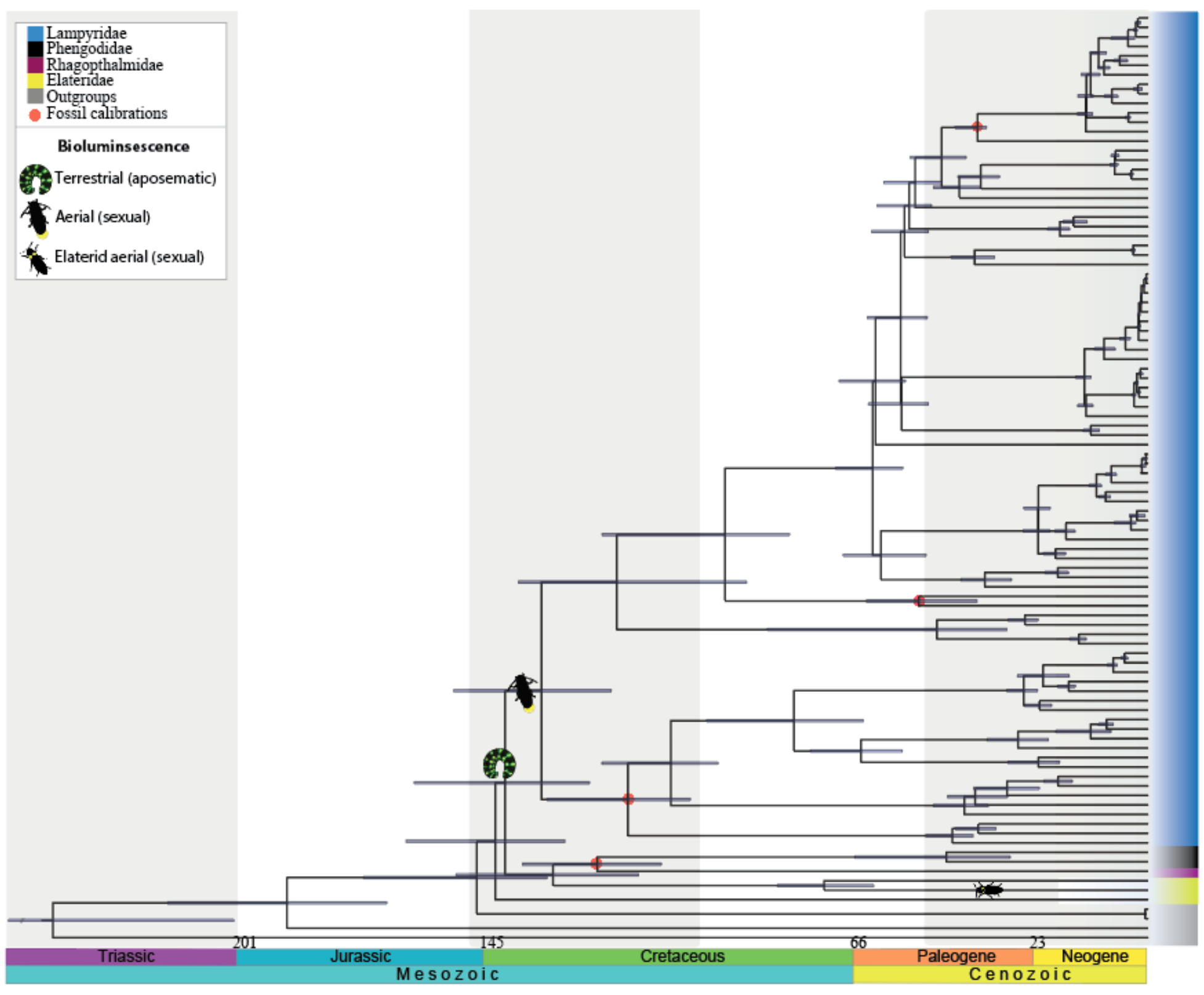

Figure 1. Divergence time calibrated phylogeny of Elateroidea using LN and BD (based on data from Martin et al., 2019) with results of ancestral state reconstruction for both terrestrial and aerial bioluminescence depicted at appropriate nodes. Grey bars to the back of the figure represent 50 million years. 


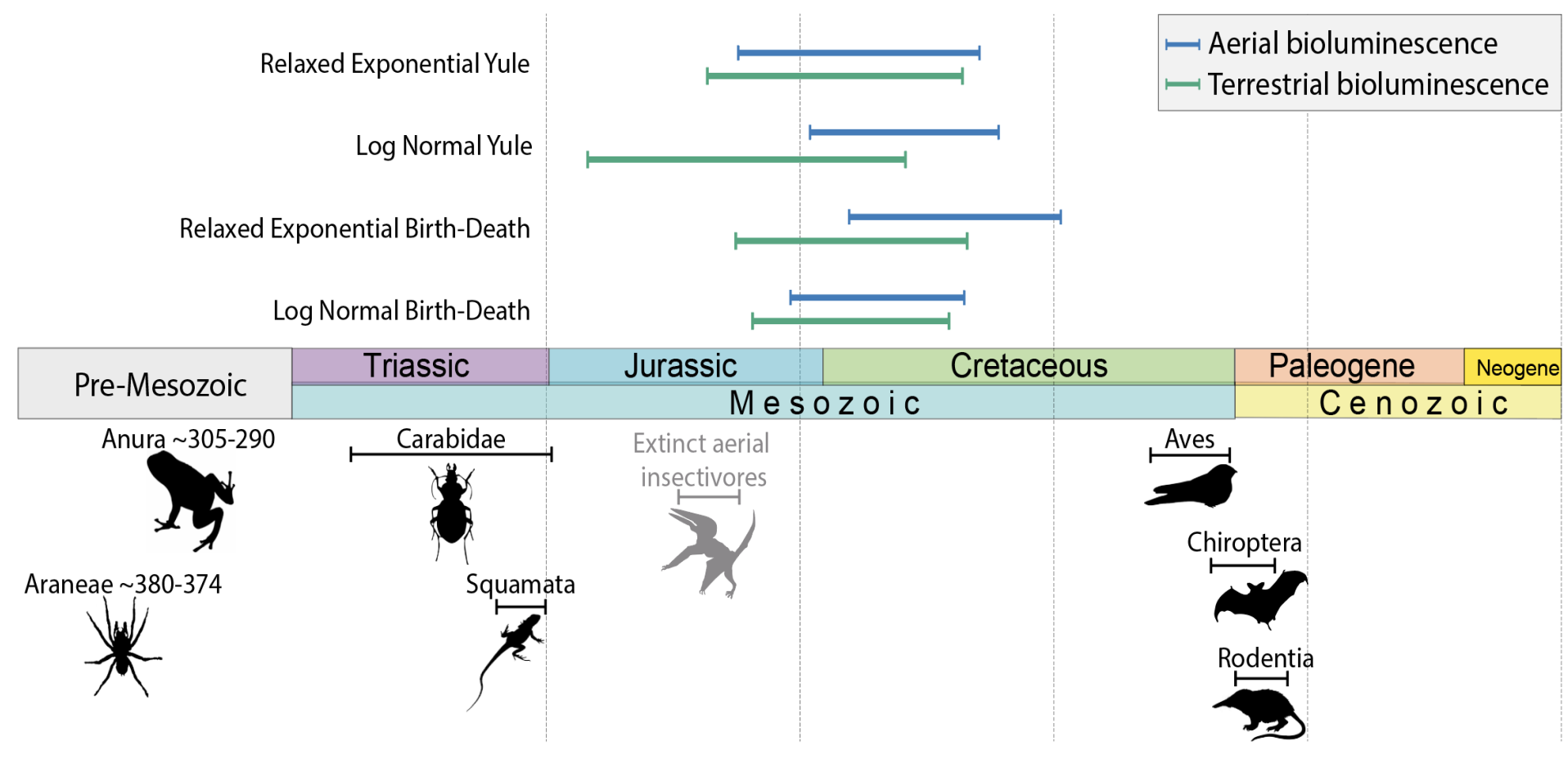

Figure 2. Comparison of divergence time estimates for nodes representing the origins of both terrestrial (blue line) and aerial (blue line) bioluminescence and with published clade origin ages for potential extant (black) and extinct (grey) predator groups. Times written out for Anura and Araneae due to age and figure constraints. Dotted vertical lines represent 50 million-year intervals. 


\section{Supplementary Material}

\begin{tabular}{lcl}
\hline Fossil & Age (mya) & Clade \\
\hline Protoluciola albertalleni & 99 & Luciolinae \\
Cretophengodes azari & 99 & (Rhagophthalmidae + Phengodidae) \\
Photinus kazantsevi & 36.2 & Photinus \\
Phausis fossilis & 25 & Lamprohizinae
\end{tabular}

Supp Table 1: Fossils used in divergence time estimation with their relative age, placement, and dataset they were applied to.

\begin{tabular}{cccc}
\hline Tree & Clock & Terrestrial & Aerial \\
\hline BD & LN & 141.17 & 133.18 \\
& & $(122.63-161.17)$ & $(117.86-152.47)$ \\
BD & RE & 129.87 & 110.30 \\
& & $(117.39-164.44)$ & $(99.36-140.97)$ \\
Yule & LN & 160.77 & 124.06 \\
& & $(129.73-192.69)$ & $112.65-148.25$ \\
Yule & RE & 139.51 & 134.60 \\
& & $(118.78-169.69)$ & $(115.69-163.76)$ \\
\hline
\end{tabular}

Supp Table 2. Divergence time estimates for nodes reconstructed to be the origins of terrestrial and aerial bioluminescence under different tree and clock models with each dataset. LN- Log Normal, RE- Relaxed Exponential, BD- Birth-Death. 
bioRxiv preprint doi: https://doi.org/10.1101/2021.11.22.469605; this version posted November 23, 2021. The copyright holder for this preprint (which was not certified by peer review) is the author/funder, who has granted bioRxiv a license to display the preprint in perpetuity. It is made available under aCC-BY-NC-ND 4.0 International license.

non-bioluminescence

Terrestrial bioluminescence only

Aerial \& terrestial bioluminesence

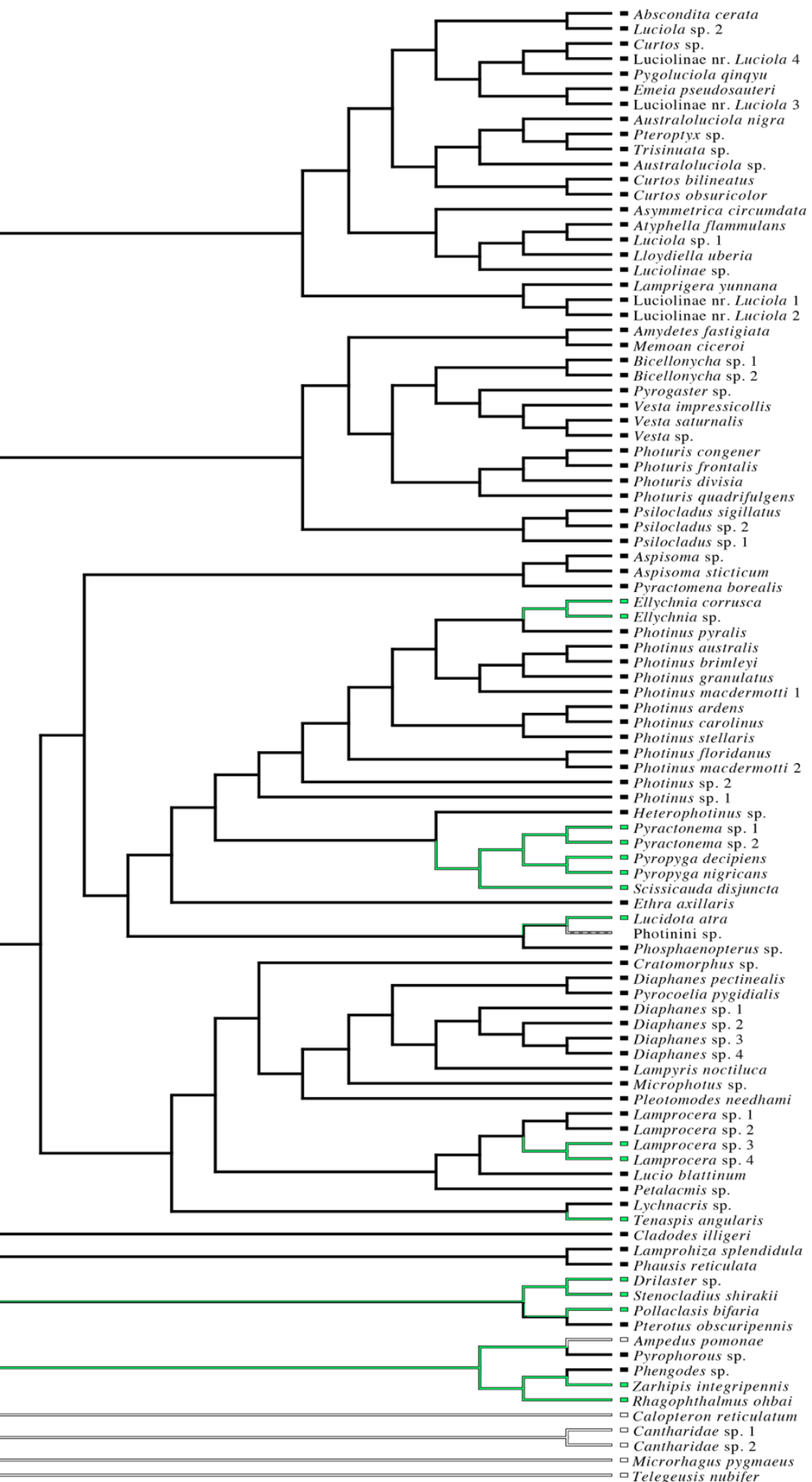

Supp. Figure 1. Maximum parsimony ancestral state reconstruction of bioluminescence in beetles. 